\title{
Database Design on Customer Relationship Management System
}

\author{
Yanmei Wang \\ College of Information Science and Technology, Bohai University, Jinzhou, 121013, China \\ 19296571@qq.com
}

Keywords: customer relationship management system; CRM; database design; conceptual structure design; logical structure design

\begin{abstract}
Customer relationship is occurred around the customer life cycle and the development of the information collection. This paper is based on the DB2 database design to provide technical support for the system development. First, DB2 database management system, including product components and database structure; Then, carries on the concept of database structure design, through the E-R model expressed entities, attributes, and relations between entities; Finally, database logic structure design, mainly "Salesman, Contact, the Product and the Customer" four entities such as logical structure. In this paper, the application of research results, to improve the efficiency and quality of software development, and promote the management informationization level, improve the economic benefit and core competence plays an important role in such aspects.
\end{abstract}

\section{Introduction}

In the traditional enterprise customer information management model, the leader and sales workers by manual approach to customer information recorded on their laptop or computer, the information is not updated in time and sharing. Therefore, often can cause the loss of customer information, or make the product submission period delay cause unnecessary loss, may be because the information loss and missed opportunities. Application of customer information management system design, computer and database technology to the enterprise customer information to conduct a comprehensive management is a new type of management mode. Customer relationship is occurred around the customer life cycle and the development of the information collection. Customer relationship management is the enterprise to enhance core competitiveness, using the corresponding information technology and Internet technology to coordination between enterprises and customers in sales, marketing and service of interaction, so as to enhance their management style, to provide customers innovative personalized customer interaction service process [1]. The ultimate goal is to attract new customers, retain old customers as well as the existing customers into loyal customers, increase market share. Database design is an important work for software development phase, the means for a given application environment, constructing the optimal database model, establish a database and application systems, to store data effectively and meet the application requirements of various users.

\section{DB2 Database Management System}

IBM DB2 is the IBM developed a set of relational database management system, mainly used in large application system, has good scalability, and can support from mainframes to a single user environment, apply to all common server operating systems’ platform. Provides a high level of data utilization, integrity, security, and recoverability, as well as small to large scale application execution ability, has the basic function of the has nothing to do with the platform and SQL command. Used the data classification technology, can make the mainframe data easily download to LAN database server, make the client/server users and applications can access mainframe data based on LAN, and makes the database localization and transparency of the remote connection. Have a very complete query optimizer, its external connection improves query performance, and support multitasking parallel query. 
DB2 database management system has the following advantages [2, 3]: (1) open/portability. From the network protocol support to the programming interface for the application development, database stored procedures and triggers, distributed operation between the server and DB2 are based on the latest international standards; (2) processing performance. IBM invented the relational database and optimization technology, and continuous development, DB2 in various performance tests of leading position; (3) the ability of parallel. DB2 support bitmap index and object relations, has better scalability and performance; (4) distributed database. The processing of distributed database and DB2 connect function based on the core, do not need to use other products accessories. Performance is good, easy to use, reduce expenditure; (5) the operation is simple. DB2 provides a GUI and command line at the same time, operation is the same in the Windows and Unix; (6) replication ability. DB2 provides the best efficiency and open replication, provides automated conflict detection and solving methods; (7) support for electronic commerce. DB2 is the foundation of e-commerce, provides a JDBC interface, can write Java language stored procedures, and user-defined functions; (8) support for business intelligence. IBM business intelligence solutions have data mining tools; (9) software quality and reliability.

DB2 database's product components are as shown in Fig. 1.

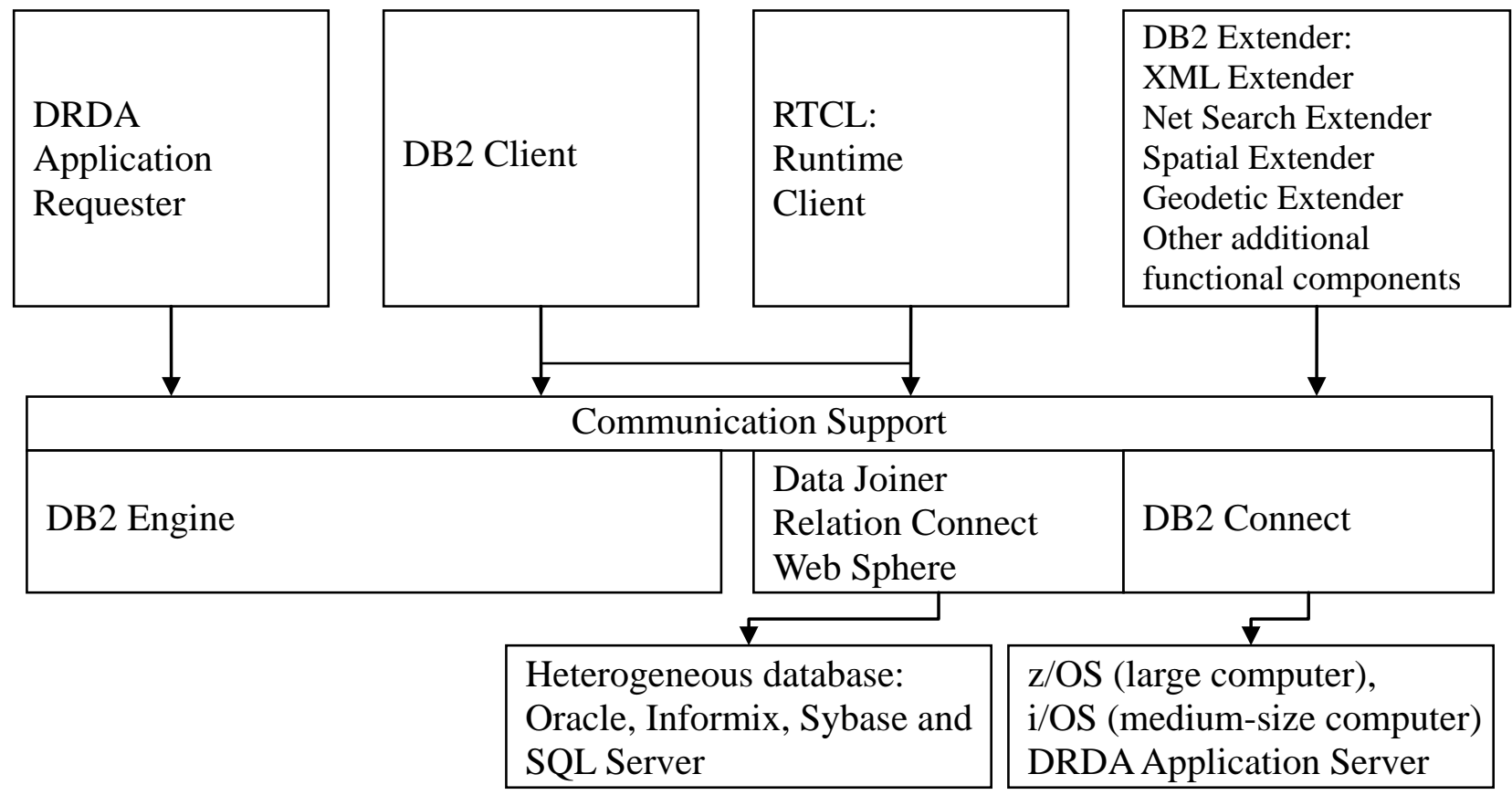

Fig. 1. Product components of DB2 database

DB2 UDB (Universal Database) Database structure is shown in Fig. 2.

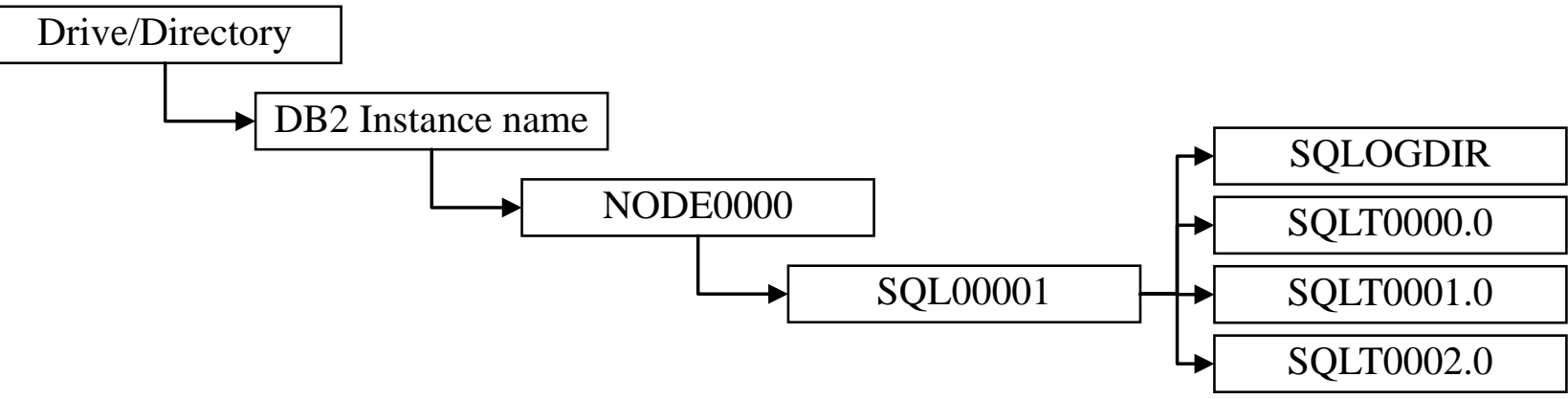

Fig. 2. Product components of DB2 database

Fig. 2, the Drive/Directory, specified in the Create database command Drive or Directory; DB2 Instance name, the name of the DB2 Instance owner. NODE0000 is database partition number. 0 means non-partitioned database; SQL00001, starting from 1 database ID; SQLOGDIR is the default log directory database; SQLT0000.0 Syscatspace catalog table space; SQLT0001.0, temporary tablespace Tempspace1; SQLT0002.0, user table space Userspace1. 


\section{Conceptual Structure Design on Database}

Conceptual structure design is the most commonly used tool E-R Diagram (Entity Relationship Diagram), E-R Diagram provides the said entities, attributes, and contact method, is used to describe the conceptual model of the real world, [4]. Reference literature [5-8], the concept of system database structure design result is shown in Fig. 3.

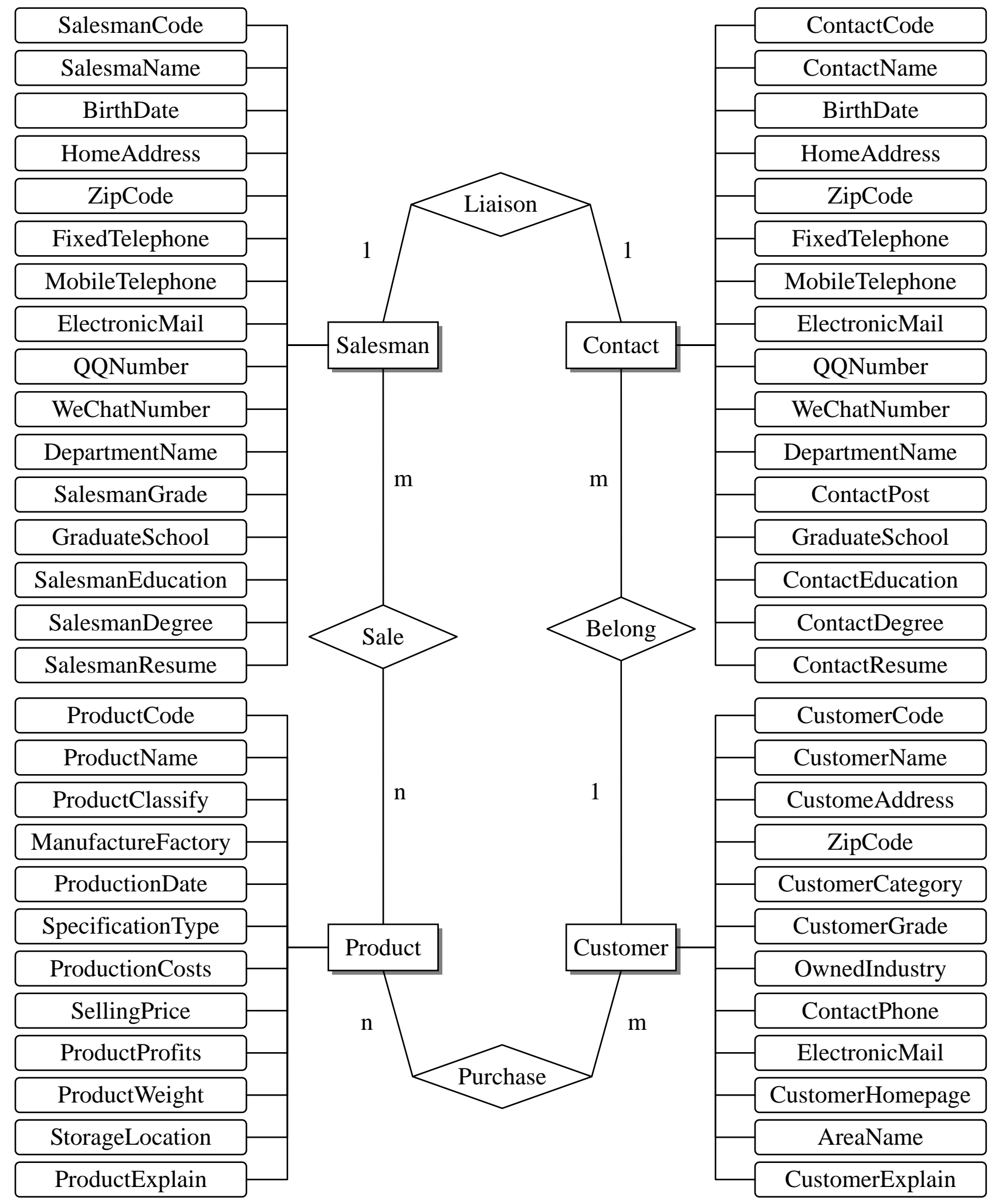

Fig. 3. Conceptual structure design on customer relationship management system 


\section{Logical Structure Design on Database}

Structure design is one or more logical structure refers to the specific set of data elements. In order to establish a database of the user's requirements, the need to convert the conceptual model to a particular DBMS support data model. Its task is to convert the conceptual model to particular DBMS support data model, the process of the need to consider the characteristics of the specific data model and the performance of DBMS. E-R diagram of an entity can be converted into a relational model, entity is the relationship of attribute and the entity's code is the relationship code. DB2 database includes a variety of data types, this system USES the "char, varchar, date, smllint and clob" of 5 kinds of data type [9]. "Salesman, Contact, the Product and the Customer" four entities such as database logical structure design results are shown in Table 1.

Table 1. Logical Structure Design on customer relationship management system

\begin{tabular}{|c|c|c|c|c|c|c|c|}
\hline \multicolumn{4}{|c|}{ "Salesman" Table } & \multicolumn{4}{|c|}{ "Contact" Table } \\
\hline No & Fields Name & Type & Bytes & No & Fields Name & Type & Bytes \\
\hline 1 & SalesmanCode & char & 10 & 51 & ContactCode & char & 10 \\
\hline 2 & SalesmaName & varchar & 30 & 52 & ContactName & varchar & 30 \\
\hline 3 & BirthDate & date & 4 & 53 & BirthDate & date & 4 \\
\hline 4 & HomeAddress & varchar & 500 & 54 & HomeAddress & varchar & 500 \\
\hline 5 & ZipCode & char & 6 & 55 & ZipCode & char & 6 \\
\hline 6 & FixedTelephone & varchar & 50 & 56 & FixedTelephone & varchar & 50 \\
\hline 7 & MobileTelephone & varchar & 50 & 57 & MobileTelephone & varchar & 50 \\
\hline 8 & ElectronicMail & varchar & 100 & 58 & ElectronicMail & varchar & 100 \\
\hline 9 & QQNumber & varchar & 10 & 59 & QQNumber & varchar & 10 \\
\hline 10 & WeChatNumber & varchar & 30 & 60 & WeChatNumber & varchar & 30 \\
\hline 11 & DepartmentName & varchar & 100 & 61 & DepartmentName & varchar & 100 \\
\hline 12 & SalesmanGrade & smllint & 2 & 62 & ContactPost & smllint & 2 \\
\hline 13 & GraduateSchool & varchar & 100 & 63 & GraduateSchool & varchar & 100 \\
\hline 14 & SalesmanEducation & varchar & 50 & 64 & ContactEducation & varchar & 50 \\
\hline 15 & SalesmanDegree & varchar & 50 & 65 & ContactDegree & varchar & 50 \\
\hline 16 & SalesmanResume & clob & 3000 & 66 & ContactResume & clob & 3000 \\
\hline \multicolumn{4}{|c|}{ " Product" Table } & \multicolumn{4}{|c|}{ "Customer" Table } \\
\hline No & Fields Name & Type & Bytes & No & Fields Name & Type & Bytes \\
\hline 21 & ProductCode & char & 10 & 71 & CustomerCode & char & 10 \\
\hline 22 & ProductName & varchar & 200 & 72 & CustomerName & varchar & 200 \\
\hline 23 & ProductClassify & varchar & 50 & 73 & CustomeAddress & varchar & 500 \\
\hline 24 & ManufactureFactory & varchar & 200 & 74 & ZipCode & char & 6 \\
\hline 25 & ProductionDate & date & 4 & 75 & CustomerCategory & varchar & 20 \\
\hline 26 & SpecificationType & varchar & 100 & 76 & CustomerGrade & smllint & 2 \\
\hline 27 & ProductionCosts & decimal & 8,2 & 77 & OwnedIndustry & varchar & 8 \\
\hline 28 & SellingPrice & decimal & 8,2 & 78 & ContactPhone & varchar & 50 \\
\hline 29 & ProductProfits & decimal & 8,2 & 79 & ElectronicMail & varchar & 50 \\
\hline 30 & ProductWeight & decimal & 8,2 & 80 & CustomerHomepage & varchar & 200 \\
\hline 31 & StorageLocation & varchar & 100 & 81 & AreaName & varchar & 50 \\
\hline 32 & ProductExplain & clob & 3000 & 82 & CustomerExplain & clob & 3000 \\
\hline
\end{tabular}




\section{Conclusion}

Customer relationship management is the enterprise in order to improve the core competitiveness, by improving the level of service to customers, improve customer satisfaction and loyalty of establish customer-focused business philosophy; By conducting systematic theoretical research, optimizing enterprise organization system and the business process implementation in enterprise's marketing, sales, service, technical support and other related fields with customers, to improve the new management system of the relationship between enterprises and customers; Enterprises through technical investment, set up to collect, track and analyze customer information system, to create and use advanced information technology, software and hardware, and the optimization of management methods and solutions are combined. In this paper, based on the DB2 database design, system development and provides a feasible solution, to improve the efficiency and quality of software development, and promote the management informationization level, improve the economic benefit and core competitiveness plays an important role in such aspects.

\section{References}

[1] Farnoosh Khodakarami, Yolande E. Chan, "Exploring the role of customer relationship management (CRM) systems in customer knowledge creation," Information \& Management, vol. 51, no. 1, pp. 27-42, 2014.

[2] Hebei bocay network, "Analysis of the advantages and disadvantages of DB2 9 database," http://www.hbrc.com/rczx/shownews-3151143-35.html, 2016-6-20.

[3] DOC88, "Advantages and characteristics of DB2 database," http://www.doc88.com/p-1146848921894.html, 2016-6-20.

[4] Z. Y. Duan, "Database Design Methodology," Journal of Nanchang College of Education, vol. 20, no. 4, pp. 85-86, 2005.

[5] Alex D. Stein, Michael F. Smith, Richard A. Lancioni, "The development and diffusion of customer relationship management (CRM) intelligence in business-to-business environments," Industrial Marketing Management, vol. 42, no. 6, pp. 855-861, 2013.

[6] J. F. Liu, W. N. He, "Development of coal industry CRM system based on SSH lightweigh architecture," Electronic Design Engineering, vol. 23, no. 5, pp. 41-43, 2015.

[7] Abeer Khan, Nadeem Ehsan, Ebtisam Mirza, Sheikh Zahoor Sarwar, "Integration between Customer Relationship Management (CRM) and Data Warehousing," Procedia Technology, vol. 1, pp. 239-249, 2012.

[8] X. Y. Wei, "The design and implementation of CRM system based on B/S enterprise sales management," Automation \& Instrumentation, vol. 39, no. 5, pp. 151-152, 2016.

[9] wengn, "DB2 data type," http://wengn.iteye.com/blog/1471968, 2016-6-21. 